\title{
Relative Gains in the Shadow of a Trade War
}

\author{
Eddy S.F. Yeung $\odot$ and Kai Quek $\odot$
}

\begin{abstract}
When do people care about relative gains in trade? Much of the international relations scholarship — and much of the political rhetoric on trade-would lead us to expect support for a trade policy that benefits ourselves more than it benefits others. Yet, a large interdisciplinary literature also points to the prevalence and importance of other-regarding preferences, rendering the conventional wisdom contestable. We investigate whether and how relative gains influence trade preferences through an original survey experiment in the midst of the China-US trade war. We find that in a win-win scenario, relative gains shape trade opinion: if both sides are gaining, people want to gain more than their foreign trade partner. However, these considerations are offset in a win-lose scenario where the other side is losing out. Relative-gains considerations causally affect opinion on trade, but not in a "beggar-thy-neighbor" or even a "beggar-thyrival" situation. These findings contribute to our understanding of the role of relative gains in international relations and provide the first experimental evidence that relative-gains considerations can be offset by other-regarding preferences in international trade.
\end{abstract}

I will use tariffs when they are needed, but the difference between me and Trump is that I will have a strategy - a plan—to use those tariffs to win.

—Joe Biden, May $2020^{1}$

Relative-gains considerations often feature in the political rhetoric on trade. ${ }^{2}$ The raison d'être of international trade lies in generating mutual benefits for all trading countries, but both politicians and the public seem to have become increasingly concerned about winning against their trade partner, instead of focusing on their own absolute gains from trade. ${ }^{3}$ Relative-gains considerations also underlie the recent

1. Quoted in David Lawder and Trevor Hunnicutt, "Pulled in Many Directions, Biden May Keep Trump's China Tariffs in Place,” Reuters, 8 September 2020.

2. Relative-gains considerations are concerns over how the home state "fare[s] compared to other states." Snidal 1991b, 703 .

3. For example, both Democratic and Republican senators in the United States have stressed the importance of winning - or not losing - against China in international trade. Bernie Sanders said during his presidential campaign: "Since the China trade deal I voted against, America has lost over 3 million manufacturing jobs. It's wrong to pretend that China isn't one of our major economic competitors. When we are in the White House we will win that competition by fixing our trade policies" (quoted in David Frum, "China Is a Paper Dragon," The Atlantic, 3 May 2021). Regarding the US-China Phase 1 trade agreement,

International Organization 76, Summer 2022, pp. 741-65

(C) The Author(s), 2022. Published by Cambridge University Press on behalf of The IO Foundation. This is an Open Access article, distributed under the terms of the Creative Commons Attribution licence (https:// creativecommons.org/licenses/by/4.0/), which permits unrestricted re-use, distribution, and reproduction in any medium, provided the original work is properly cited.

doi:10.1017/S0020818322000030 
trade war between China and the US, as seen in how politicians such as Donald Trump framed the issue, using the rhetoric of "win" or "lose" to emphasize how the US is performing relative to China. ${ }^{4}$ While mutual gains lie at the heart of international trade, relative gains have become prominent in the politics of trade.

Despite the prevalence of relative-gains considerations in the political rhetoric, few studies have explored whether and how such considerations influence trade preferences. On the one hand, while the conventional wisdom in international political economy suggests that trade preferences are predominantly guided by economic self-interest, a growing body of research now shows that sociotropic preferences can also affect opinion on trade..$^{5}$ On the other hand, while the issue of relative gains has long been discussed by international relations (IR) scholars, few have connected it directly with the study of domestic trade preferences.

We investigate how relative gains influence trade preferences through an original survey experiment in the midst of the China-US trade war. We find that in a win-win scenario, relative gains shape trade opinion: if both sides are gaining, people want to gain more than their foreign trade partner. However, these considerations are offset in a win-lose scenario where the other side is losing out - whether the other side is China in particular, or an unnamed trade partner in general. Relative-gains considerations can shape trade preferences, but they can also be countervailed by other-regarding concerns if the trade policy involves a win-lose scenario. Additional analyses of the open-ended responses reinforce our conclusions.

Our study is the first to experimentally investigate how relative gains and otherregarding preferences interact in trade. We argue that it is necessary to study them jointly, rather than in isolation from one another, to better understand the role of relative gains in trade opinion. Our study thus extends previous research that found other-regarding concerns operating toward domestic others, ${ }^{6}$ as well as the latest experimental work that found concerns over fairness shaping trade preferences. ${ }^{7}$ By studying not only win-win but also win-lose settings, we show that while relative gains influence attitudes toward trade, other-regarding considerations-specifically concerns over losses in a trade partner-also shape trade preferences and can offset relative-gains

Marco Rubio commented: "This is not a win. Investing American capital in China may earn better returns in the short term. But it will come at a tremendous cost in the long term." (Marco Rubio, "Marco Rubio: Investing in China Is Not a Good Deal," New York Times, 17 January 2020). Lindsey Graham, another Republican senator, welcomed the trade agreement but added that "Chinese trade behavior has been very predatory against American interests," and hoped that the agreement would "lead to further trade deals that are truly a win-win" (Lindsey Graham, "Graham Applauds New China Trade Deal," 15 January 2020), available at <https://www.lgraham.senate.gov/public/index.cfm/2020/1/graham-applaudsnew-china-trade-deal>.

4. For example, Trump tweeted: "When a country (USA) is losing many billions of dollars on trade with virtually every country it does business with, trade wars are good, and easy to win. Example, when we are down $\$ 100$ billion with a certain country and they get cute, don't trade anymore-we win big. It's easy!" (quoted in Linda Qiu, "President Trump's Exaggerated and Misleading Claims on Trade," New York Times, 6 March 2018).

5. For example, Guisinger 2017; Hearn 2020; Lü, Scheve, and Slaughter 2012; Mansfield and Mutz 2009.

6. Lü, Scheve, and Slaughter 2012.

7. Brutger and Rathbun 2021. 
considerations. Finally, by showing that beliefs about relative gains at the societal level can influence personal sentiments on trade, our findings provide additional support for the idea that trade preferences are also guided by sociotropic motivations. ${ }^{8}$

\section{Trade Preferences and Relative Gains}

Conventional wisdom in international political economy suggests that individual trade preferences are predominantly guided by economic self-interest. The Heckscher-Ohlin model shows that free trade would increase (or decrease) the real earnings of owners of factors of production that are abundant (or scarce) relative to foreign countries. ${ }^{9}$ The model predicts that trade preferences are shaped by individual factor endowments, and several studies have provided evidence for it. ${ }^{10}$ The RicardoViner model, on the other hand, predicts that people in export-oriented (or importoriented) sectors will support (or oppose) free trade. ${ }^{11}$ Studies providing empirical support include Beaulieu, Irwin, and Kaempfer and Marks, ${ }^{12}$ and the model has also received joint support along with the Heckscher-Ohlin model. ${ }^{13}$ At the same time, however, a sizable body of research also suggests trade preferences are not merely guided by the individual's direct material self-interest. ${ }^{14}$

In particular, mainstream neorealist scholarship would predict that trade preferences are affected by relative-gains considerations. This is because "the general insecurity of international anarchy leads states to worry not simply about how well they fare themselves (absolute gains) but about how well they fare compared to other states (relative gains)." ${ }^{15}$ As the relative power and influence of a country depend on relative gains rather than absolute gains, "relative gain is more important than absolute gain." 16 Given states' pursuit of relative gains, international cooperation can become a zero-sum, or near-zero-sum, game. ${ }^{17}$

Relative-gains considerations mean that "states compare their absolute outcome to the absolute outcomes of other states." 18 It follows that a win-win trade policy where

8. Fordham 2008; Guisinger 2017; Hearn 2020; Mansfield and Mutz 2009.

9. Stolper and Samuelson 1941.

10. See Baker 2005; Balistreri 1997; Beaulieu 2002a; Beaulieu and Magee 2004; O’Rourke and Sinnott 2001; Ray 1987; Scheve and Slaughter 2001.

11. Jones 1971; Samuelson 1971.

12. Beaulieu 2002b; Irwin 1994, 1996; Kaempfer and Marks 1993.

13. Baldwin and Magee 2000; Mayda and Rodrik 2005.

14. Education, for example, can influence one's support for trade through channels that are unrelated to individual skills and economic self-interest. Hainmueller and Hiscox 2006 argued that because individuals with college education tend to have a greater exposure to economic ideas and information, they are more supportive of free trade. Rho and Tomz 2017 experimentally showed that economic ignorance prevented many people from understanding the distributional consequences of trade policy, which reduced their ability to identify and support a more self-serving trade policy.

15. Snidal 1991b, 703.

16. Waltz 1959, 198.

17. Grieco 1988a, 1988b, 1990; Snidal 1991a, 1991b; Waltz 1959.

18. Snidal 1991a, 389. 
domestic gains outweigh the trade partner's gains would be preferred to a win-win policy where foreign gains outweigh domestic gains. It also follows that a win-lose trade policy, where domestic gains are derived at the expense of the trade partner, would be even better from the relative-gains perspective, even if the domestic absolute gains remain the same. ${ }^{19}$ Such relative-gains calculations can impede international cooperation, as several models have shown. ${ }^{20}$

Yet, relative gains do not always impede international trade. ${ }^{21}$ For example, relative-gains concerns in the economic realm can be less salient than those in the security realm. ${ }^{22} \mathrm{~A}$ state may also favor a policy where foreign gains outweigh domestic gains if the absolute gains it derives from the policy would create relative gains vis-à-vis other foreign states. ${ }^{23}$ Even if states have a natural tendency to compete, international economic cooperation may still be in their strategic interests. ${ }^{24}$ However, if a trade policy is likely to affect the future interactions between home and foreign states, relative-gains concerns will kick in. ${ }^{25}$ In particular, if people believe that relative economic advantages can be translated into relative military advantages, or that the trade partner is a potential security threat, then relative gains in trade are likely to be important. ${ }^{26}$ Theorizing relative gains as security externalities, Gowa and Mansfield found that free trade took place more frequently within, but not across, military alliances, suggesting that states take relative gains into consideration on the issue of trade. ${ }^{27}$ Mastanduno argued that America's shift to a more protectionist trade policy in the late 1980s showed "clear signs of relative gains-seeking behavior ... in the US policy process." 28

Relative-gains concerns can affect trade preferences at the individual level through sociotropic considerations. A large body of research has established the importance of sociotropic motivations in policy preferences. Early work by Kinder and Kiewiet found a sociotropic voting pattern in American politics, where voters tend to focus on collective-level instead of individual-level information. ${ }^{29}$ Sociotropic influence is highly relevant to how political perceptions form and may even outweigh egotropic considerations. ${ }^{30}$ Mansfield and Mutz found that trade preferences depended on how people perceived the economic impact of international trade on the US as a whole, and that in-group favoritism could affect opinion on trade. ${ }^{31}$ Relative-gains

19. This follows from the standard conceptualization of relative gains, that is, the domestic absolute outcome relative to the foreign absolute outcome. The key is the distance between domestic and foreign payoffs. See Grieco 1998b; Snidal 1991a; Waltz 1959.

20. Grieco 1988b; Powell 1991; Snidal 1991b.

21. Busch and Reinhardt 1993; Morrow 1997; Snidal 1991a.

22. Lipson 1984.

23. Werner 1997.

24. Glaser 1994.

25. Baldwin 1993; Matthews 1996.

26. Snidal 1991b, 703; Waltz 1959, 1979.

27. Gowa and Mansfield 1993. See also Gowa 1989.

28. Mastanduno 1991, 109.

29. Kinder and Kiewiet 1981.

30. Hainmueller and Hopkins 2015; Hearn 2020; Mutz 1992; Sears and Funk 1990.

31. Mansfield and Mutz 2009. See also Mutz and Kim 2017; Sabet 2013. 
considerations operate here insofar as people would prefer a trade policy that brings greater gains to the domestic in-group relative to the foreign out-group.

Previous work has focused on the role of relative gains under a win-win trade policy. But what happens when a trade policy involves a win-lose scenario? The underlying expectation in the literature is that the same logic of relative gains would apply: individuals would support a win-lose trade policy as long as their country is on the winning side. We argue, however, that a win-lose trade policy would be characterized not only by its relative-gains implications but also by its other-regarding ramifications. The two are not mutually exclusive. When a winlose trade policy is implemented, both relative-gains and other-regarding concerns can be triggered. Relative-gains considerations may be mitigated by the other-regarding concerns that characterize human behavior in general.

That human beings have other-regarding social preferences is one of the most widely documented facts in social science. ${ }^{32}$ In economics, many laboratory experiments have found individuals deviating from the "rationality" predicted by standard game-theoretic models in response to social preferences. Examples include how human players respond to the ultimatum game, ${ }^{33}$ the dictator game, ${ }^{34}$ and the trust game. ${ }^{35}$ Economists have formalized the ideas of altruism and inequity aversion, ${ }^{36}$ and found experimental evidence for such behavior. ${ }^{37}$ Recent research has also found neural evidence for altruistic and inequity-averse preferences in human beings. ${ }^{38}$

Such other-regarding motivations can influence economic decisions and policy preferences. ${ }^{39}$ Examining anthropological, experimental, and survey evidence, Fong, Bowles, and Gintis suggested that reciprocity motives often play an important role in shaping public opinion on redistribution. ${ }^{40}$ Relatedly, in Johnson and colleagues' experiments, people displayed a high willingness to punish free riders in public goods games. ${ }^{41}$ On trade issues in particular, Funk found from the American National Election Studies data that societal motivations could be important in determining policy attitudes. ${ }^{42}$ Lü, Scheve, and Slaughter found that people were more supportive

32. In line with the behavioral economics literature, we view other-regarding preferences as a form of behavioral motivation that is distinct from egoism. That is, other-regarding preferences are exhibited when an individual cares about others' outcomes in a non-egoistic manner (Fehr and Fischbacher 2002; Fehr and Schmidt 2006). Thus, relative-gains concerns do not constitute other-regarding preferences but instead demonstrate egoism, because "the gains of others give them the possibility to do harm to one's future egoistic ends through the use of coercion" (Brutger and Rathbun 2021, 884; see also Powell 1991).

33. Güth, Schmittberger, and Schwarze 1982.

34. Forsythe et al. 1994.

35. Berg, Dickhaut, and McCabe 1995.

36. For example, Andreoni 1990; Fehr and Schmidt 1999.

37. For example, Andreoni and Miller 2002; Bellemare, Kröger, and van Soest 2008; Engelmann and Strobel 2004; Fehr and Fischbacher 2002.

38. Filkowski, Cochran, and Haas 2016; Tricomi et al. 2010.

39. Reviewed in Fehr and Fischbacher 2002. See also Charness and Rabin 2002; Levitt and List 2007.

40. Fong, Bowles, and Gintis 2006.

41. Johnson et al. 2009.

42. Funk 2000. 
of protecting a domestic industry when their monthly income was higher than the monthly income the average worker in that industry earns. ${ }^{43}$ While this study does not consider relative gains in the IR sense or touch on the welfare consequences for foreign states, it demonstrates the role of inequity aversion in public support for protectionism.

We believe that such social preferences can also extend to foreign citizens: people want themselves and their national in-group to do well, but they also do not want to see themselves doing well at the direct expense of others. Research has shown that people have a strong psychological need for a positive self-image, and that otherregarding motivations in human beings can also extend toward out-group members. ${ }^{44}$ Recent work has also suggested the prevalence and importance of social preferences in IR. ${ }^{45}$ Building on prior work, we argue that other-regarding considerations can interact with relative-gains concerns in individual trade preferences. Consider a trade policy that benefits the domestic economy at the expense of a foreign economy. If relative-gains considerations are strong while social preferences are weak, then domestic citizens are likely to support this policy. Yet if social preferences are strong while the relative-gains considerations are weak, domestic citizens may oppose it. In this way, the relevance of relative gains in shaping public opinion toward trade is conditional on the existence and salience of other-regarding preferences.

\section{Past Experimental Approaches}

Three previous experiments have touched on the relationship between trade preferences and relative gains. Rousseau conducted an experiment with undergraduates at four US universities, and separately with the general public of Virginia, that asked: "Would you support or oppose an international trade agreement that results in small economic gains by the United States but major economic gains by [Russia / China / Japan / Canada]?"46 The trade partner was the experimental treatment, with one country randomly assigned to each respondent. Respondents were more likely to support the agreement when the trade partner was Russia or Canada than when it was China or Japan.

43. Lü, Scheve, and Slaughter 2012.

44. For instance, by manipulating the payoffs that the subjects and their partners receive in three different experimental games, Fehr, Glätzle-Rützler, and Sutter 2013 found that other-regarding behavior was prevalent in subjects regardless of whether their partners were deemed in-group or out-group members. But see Bernhard, Fischbacher, and Fehr 2006 and Goette, Huffman, and Meier 2006, who suggested that otherregarding preferences among adults, in the form of altruism, can be affected by parochialism.

45. See, for example, Brutger and Rathbun 2021 and Hearn 2014 on trade. Hearn found that perceptions of unfair trade practices can reduce support for free trade. See Naoi 2020, 342-43 for an excellent review of how fairness and reciprocity shape protectionist sentiments. On the role of fairness in international bargaining, see Kertzer and Rathbun 2015.

46. Rousseau 2002. 
Manipulating not only the trade partner but also the distribution of gains in a factorial experiment, Herrmann, Tetlock, and Diascro tested whether American citizens behaved like "intuitive neorealists" in trade. ${ }^{47}$ They produced twelve sets of hypothetical scenarios that varied the relative gains to the US; the identity of the trade partner (ally or enemy); and the affluence of the trade partner (rich or poor). The results indicated that a sizable proportion of the respondents thought along intuitive neorealist lines: they were most supportive of trade restrictions when the US suffered a relative loss vis-à-vis a wealthy trade partner that was also an enemy.

More recently, Mutz and Kim ran a survey experiment on a US national sample to study the impact of in-group favoritism on trade preferences. ${ }^{48}$ By manipulating the job gains or losses for the trade partner while holding constant the job gains for the US, they evaluated whether benefiting the trade partner would affect people's support for the proposed trade policy. For the full sample, support for the trade policy was not influenced by the manipulation: respondents supported the policy as long as it benefited US jobs. However, respondents with a stronger "social dominance orientation" or with zero-sum perceptions of trade's impact on employment, who tend to be Republicans, were more opposed to the win-win trade policy that also benefited the trade partner.

Our study differs from previous studies in three ways. First, we focus on directly and experimentally manipulating the relative gains for the US vis-à-vis its trade partner. Rousseau's experiment studied the effect of the identity of the trade partner, rather than the effect of relative gains. Herrmann, Tetlock, and Diascro's experiment studied the prevalence of neorealist thinking in trade by jointly studying the distribution of gains and the political-economic status of the trade partner. Mutz and Kim's experiment, which manipulated the job gains or losses for the trade partner, did not directly test the effect of relative gains since the job-losses treatment not only introduced gains to the US but also involved inflicting harm on the trade partner, which generated other-regarding concerns in the same experiment. It is possible that no significant effect was found from the manipulation because the relativegains and other-regarding considerations countervailed one another (see earlier discussion). We avoid this complication by designing a relative-gains treatment in which both the US and its trade partner gain, except that one gains more relative to the other. Thus our study provides a direct test of the effect of relative gains and differs fundamentally from Mutz and Kim's study, which focuses on in-group favoritism.

Second, we also investigate how other-regarding preferences in trade may offset relative-gains considerations. We do so by experimentally manipulating the magnitude of the losses caused to the trade partner across two different win-lose policy scenarios. This differs from Mutz and Kim's study, which did not compare two win-lose scenarios or examine the role of other-regarding preferences in trade. It 
also differs from Herrmann, Tetlock, and Diascro's study, which did not incorporate a win-lose setting or study how other-regarding preferences interact with relative-gains concerns in trade.

Finally, we differ from Mutz and Kim in how we manipulate respondents' perceptions of the gains or losses from trade. Instead of using job gains or losses as our experimental manipulation, we directly inform our respondents of the winners and losers from trade. We avoid using job gains or losses because the international political economy literature has shown that individuals are particularly sensitive to job losses in economic issues, ${ }^{49}$ and that the mere introduction of issue framing with job losses can shift public opinion on trade by a large margin..$^{50}$ Our design allows respondents to focus squarely on the relative gains or losses from trade without the additional salience of job losses.

\section{Experimental Design}

We conducted a national survey in the US in August 2018 using Amazon Mechanical Turk $(n=1,733) .{ }^{51}$ Respondents were randomly assigned to one of eight experimental groups, which were shown different vignettes. Appendices A and B (in the online supplement) show the experimental instrument and the covariate balance across the groups.

We conducted a series of robustness checks that controlled for different sets of demographic and attitudinal variables in ordered probit regressions (see Tables A1-A4). Like Rho and Tomz, ${ }^{52}$ we also replicated our findings after reweighting the survey data to match the population benchmarks in age, gender, education, and party identification (see Appendix G). Our main conclusions remained unchanged across these robustness checks.

Our experiment begins with a scenario where the US proposes to [remove / impose] import limits on [China / Country X]. Figure 1 summarizes our experimental design.

49. Hoffman 2010; Margalit 2011.

50. Hiscox 2006.

51. Amazon Mechanical Turk (AMT) is a crowdsourcing platform that has been widely used in social science. AMT samples are significantly more diverse than traditional convenience samples, and comparable to nationally representative samples on many (but not all) demographic dimensions. Several studies testing the validity of AMT data found them to be as reliable as data from standard survey and laboratory experiments (Berinsky, Huber, and Lenz 2012; Coppock 2019; Coppock, Leeper, and Mullinix 2018; Krupnikov and Levine 2014). Other studies have shown that AMT participants are at least as attentive as-if not more attentive than-those drawn from other subject pools, such as college students (Goodman, Cryder, and Cheema 2013; Hauser and Schwarz 2016; Paolacci, Chandler, and Ipeirotis 2010) and some commonly used Internet panels (Berinsky, Huber, and Lenz 2012, 366). For these reasons, many experiments in political science have used AMT, including Huff and Kertzer's 2018 experiment on terrorism, Jones and Bejan's 2021 study on tolerance, and Rho and Tomz's 2017 survey experiment on trade preferences.

52. Rho and Tomz 2017. 


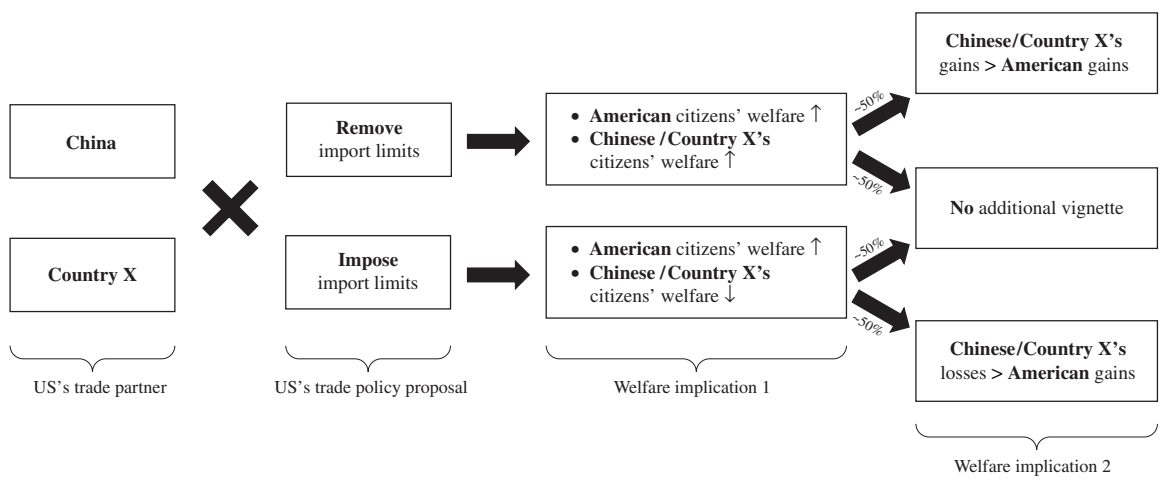

FIGURE 1. Design of study

Respondents in the "remove" scenario were told that the removal of the import limits would increase both American citizens' welfare and [Chinese / Country X's] citizens' welfare-a win-win trade policy. Half of these respondents were subsequently given an additional vignette saying that the gains enjoyed by [Chinese / Country X's] citizens would be significantly greater than the gains enjoyed by American citizens; the others were not given the additional vignette. This additional vignette imputes relative gains to the foreign country. If relative gains affect trade preferences, we should expect respondents to be less supportive of removing import limits on [China / Country $\mathrm{X}$ ] when given the additional vignette. This provides a direct test of the effect of relative gains on trade opinion.

Respondents in the "impose" scenario were told that the imposition of the import limits would increase American citizens' welfare and decrease [Chinese / Country $\mathrm{X}$ 's] citizens' welfare-a win-lose trade policy. A randomized subset of respondents were subsequently given an additional vignette saying that the losses suffered by [Chinese / Country X's] citizens would be significantly greater than the gains enjoyed by American citizens; the others were not given the additional vignette. This additional vignette implies even greater relative gains for the US under a win-lose scenario, but can also evoke greater other-regarding concerns, as foreigners are hurt more. If relative-gains considerations dominate other-regarding considerations in determining trade preferences, we should expect respondents to be more supportive of imposing the import limits on [China / Country X] when given the additional vignette. However, if other-regarding considerations dominate relativegains considerations, they should be less supportive. Here, other-regarding considerations are inferred from the data. We also check our conclusions by analyzing the motivations expressed by respondents in their open-ended responses (see next section).

The literature in social psychology would lead us to expect relative-gains considerations to prevail in the "remove" (win-win) scenario and other-regarding considerations to dominate in the "impose" (win-lose) scenario. Part of the reason is that 
humans have an innate need for a positive self-image. ${ }^{53}$ Indeed, some psychologists believe that this is the "master motive" of human beings. ${ }^{54}$ Relatedly, self-regulation theory maintains that individuals are intrinsically motivated to uphold moral standards, ${ }^{55}$ and self-determination theory proposes that people have an innate psychological need for "relatedness," which makes them intrinsically motivated to care for others. ${ }^{56}$

To uphold their positive self-image, human beings are motivated to avoid inflicting negatives on others, including foreigners. ${ }^{57}$ Recall that in the win-win scenario foreigners continue to gain from trade, whereas in the win-lose scenario they are hurt by the proposed trade policy. We should therefore expect other-regarding concerns, in the form of not wanting to hurt or take advantage of other people, to be salient in the win-lose scenario but not in the win-win scenario. ${ }^{58}$

Five nuances of the experimental design are useful to note:

- Survey instruments based on import limits are frequently used in trade opinion research. Examples include Lü, Scheve, and Slaughter; Rho and Tomz; ${ }^{59}$ and the trade sections of the American National Election Studies surveys adopted by Blonigen; Hainmueller and Hiscox; Hays, Ehrlich, and Peinhardt; and Scheve and Slaughter. ${ }^{60}$ Survey instruments manipulating welfare gains or losses for citizens (rather than countries or governments) are also common in research on trade opinion. ${ }^{61}$

- China is a useful case for exploring the relevance of relative gains because it is a country not favored by most Americans, especially in the midst of a heated trade war between the US and China. ${ }^{62}$ Thus, China provides a hard case for testing the interaction between relative-gains and other-regarding preferences in trade, compared to "Country X."

53. Crocker, Olivier, and Nuer 2009.

54. Baumeister 1998. Consistent with the social psychology literature, the economists Roland Bénabou and Jean Tirole observed that studies have "confirm[ed] the importance of such self-image concerns in explaining prosocial behavior in anonymous settings." Bénabou and Tirole 2006, 1653.

55. Reviewed in Baumeister 2010.

56. Deci and Ryan 2000, 231.

57. Brekke, Kverndokk, and Nyborg 2003; Kahneman and Knetsch 1992.

58. Prospect theory might also help us understand the results. If individuals are less risk seeking and aggressive in the domain of gains than in the domain of losses (see, for example, Davis 2000, 37; Jervis 1992; Levy 1992, 285-86), the win-lose scenario (where relative gains are made by the US) should be more conducive to other-regarding social considerations than the win-win scenario (where relative losses are incurred). We thank an anonymous reviewer for suggesting the potential relevance of prospect theory.

59. Lü, Scheve, and Slaughter 2012; Rho and Tomz 2017.

60. Blonigen 2008; Hainmueller and Hiscox 2006; Hays, Ehrlich, and Peinhardt 2005; Scheve and Slaughter 2001.

61. See, for example, Hiscox 2006; Mutz and Kim 2017; Rho and Tomz 2017.

62. In spring 2018, about half of the adult American population expressed disfavor toward China, compared to only 38 percent who reported a favorable opinion. Wike and Devlin 2018. 
- We also use Country $\mathrm{X}$ as the hypothesized trade partner because we want to study how relative-gains and other-regarding considerations interact in trade opinion independent of the influence of the trade partner's identity. Including Country $\mathrm{X}$ in our design allows us to additionally test whether and to what extent our findings are sensitive to China and the trade war. ${ }^{63}$

- In the control group of the "remove" scenario, we did not stipulate that the welfare gains were equal for the two groups of citizens. Because equal gains in trade are inherently associated with the concepts of fairness and equality, which also affect trade preferences, ${ }^{64}$ priming the respondents to think about equal gains could introduce an unintended treatment to the control group.

- We did not include the win-win welfare implication for the "impose" scenario because it goes against economic theory that imposing import limits will generate gains for both countries. Similarly, we did not include the win-lose welfare implication for the "remove" scenario because it goes against economic theory that removing import limits will cause losses for the trade partner. ${ }^{65}$

After reading the vignettes, respondents were asked how much they supported the given trade policy on a seven-point scale from 0 ("strongly oppose") to 6 ("strongly favor"). They also provided open-ended responses to explain their preferences.

\section{Experimental Results}

To test whether relative-gains considerations affect trade preferences, we compare the groups randomly assigned to the "remove" scenario-a win-win trade policy (Table 1). If relative gains are important, support for the policy should decrease when the additional vignette (relative gains for the trade partner) is introduced. As Table 1 shows, this is indeed the case when the trade partner is China: respondents' support for the policy decreased by 0.71 on the seven-point scale when they learned that Chinese gains would outweigh American gains $(p=0.0004, n=435)$. Support also decreases, but not as much, when the trade partner is Country X: respondents'

63. Political scientists, particularly in IR, often use unnamed countries in experiments. See, for example, Johns and Davies 2012; Tomz and Weeks 2013; Yarhi-Milo, Kertzer, and Renshon 2018. Forthcoming research by Brutger and colleagues has also examined the advantages of, and provided justifications for, the use of unnamed countries in survey experiments.

64. Brutger and Rathbun 2021; Hearn 2014.

65. That the US can gain in the "remove" scenario is consistent with economic theory. For a large economy like the US, removing import limits can decrease or increase its welfare-both can happen in the real world (Krugman, Obstfeld, and Melitz 2012, chapter 10). We also note that if some respondents disagreed with the vignette, we should end up having weaker average treatment effects. In the case where a randomized segment of respondents disagreed with the vignette, they would not be "treated" as intended in our experiment, thereby weakening the overall average treatment effects in the full sample. Therefore, having some respondents disagree with the vignette should weaken, rather than strengthen, our results. 
support decreased by 0.29 when they learned that Country X's gains would outweigh American gains $(p=0.0828, n=415)$. These results suggest that relative gains can affect trade opinion in a win-win scenario: if both sides are gaining, people want to gain more than their foreign trade partner. The relative-gains concerns are particularly salient when the trade partner is China.

TABLE 1. Average treatment effect among groups presented with the removal of import limits

\begin{tabular}{|c|c|c|c|c|c|c|c|c|c|}
\hline \multirow[b]{2}{*}{ Trade Partner } & \multicolumn{3}{|c|}{ No Additional Vignette } & \multicolumn{3}{|c|}{ Additional Vignette } & \multirow[b]{2}{*}{ Difference } & \multirow[b]{2}{*}{ t-statistic } & \multirow[b]{2}{*}{ p-value } \\
\hline & Mean & $S D$ & $n$ & Mean & $S D$ & $n$ & & & \\
\hline China & 4.400 & 1.921 & 215 & 3.686 & 2.218 & 220 & -0.714 & -3.584 & 0.0004 \\
\hline
\end{tabular}

Notes: The dependent variable is support for the removal of import limits, on a seven-point scale from 0 to 6 . The additional vignette says that the gains enjoyed by Chinese or Country X's citizens would be greater than the gains enjoyed by American citizens. All $t$-tests are two-tailed.

Next, we compare the groups randomly assigned to the "impose" scenario-a win-lose trade policy (Table 2). If relative-gains concerns dominate, then support for the policy should increase when the additional vignette (greater relative gains for the US) is introduced. But it does not. When the trade partner was Country X, respondents' support for the policy decreased by 0.80 on the seven-point scale $(p=0.0001, n=445)$. Surprisingly, this decrease remained substantial $(0.57)$ even when the trade partner was China $(p=0.0057, n=438)$.

TABLE 2. Average treatment effect among groups presented with the imposition of import limits

\begin{tabular}{|c|c|c|c|c|c|c|c|c|c|}
\hline \multirow[b]{2}{*}{ Trade Partner } & \multicolumn{3}{|c|}{ No Additional Vignette } & \multicolumn{3}{|c|}{ Additional Vignette } & \multirow[b]{2}{*}{ Difference } & \multirow[b]{2}{*}{ t-statistic } & \multirow[b]{2}{*}{$p$-value } \\
\hline & Mean & $S D$ & $n$ & Mean & $S D$ & $n$ & & & \\
\hline China & 3.388 & 2.065 & 219 & 2.817 & 2.231 & 219 & -0.571 & -2.779 & 0.0057 \\
\hline Country X & 3.375 & 2.084 & 224 & 2.575 & 2.087 & 221 & -0.800 & -4.048 & 0.0001 \\
\hline
\end{tabular}

Notes: The dependent variable is support for the imposition of import limits, on a seven-point scale from 0 to 6 . The additional vignette says that the losses suffered by Chinese or Country X's citizens would be greater than the gains enjoyed by American citizens. All $t$-tests are two-tailed.

These results suggest that other-regarding preferences in trade are important not only domestically ${ }^{66}$ but also internationally. Social considerations remain relevant 
even in the context of foreign rivalry amplified by a heated trade war. Relative-gains considerations can influence trade opinion, but they can also be countervailed if the trade policy presents a win-lose scenario that harms the trade partner.

The results also seem to indicate stronger relative-gains considerations and weaker social considerations when the trade partner is China. ${ }^{67}$ If this is the case, we should observe a clearer pattern from respondents who are more nationalistic. We therefore subset our analyses to study the nationalists in our sample, those likely to hold stronger anti-Chinese sentiments. ${ }^{68}$ The evidence suggests that among nationalists, relative-gains concerns are particularly salient, and social preferences more subtle, when the trade partner is China instead of Country $X$ (Figures 2 and 3). In Appendices D and E, we further show that subset analyses of (1) hawks versus doves and (2) Republicans versus non-Republicans follow a similar empirical pattern: hawks and Republicans behave like nationalists, while doves and nonRepublicans behave like non-nationalists.

(a) China as trade partner

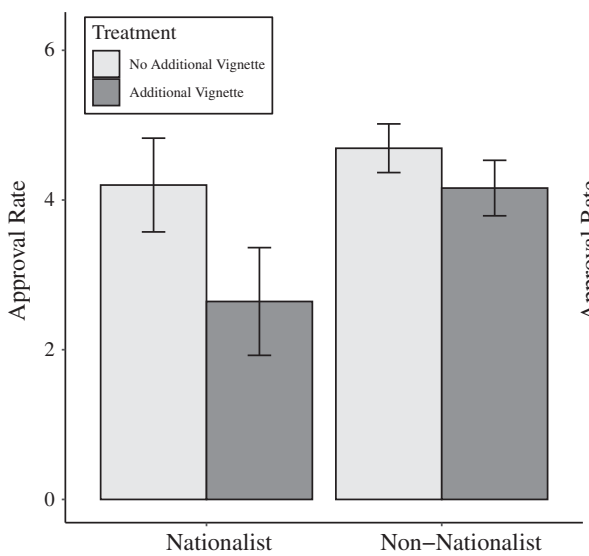

(b) Country $\mathrm{X}$ as trade partner

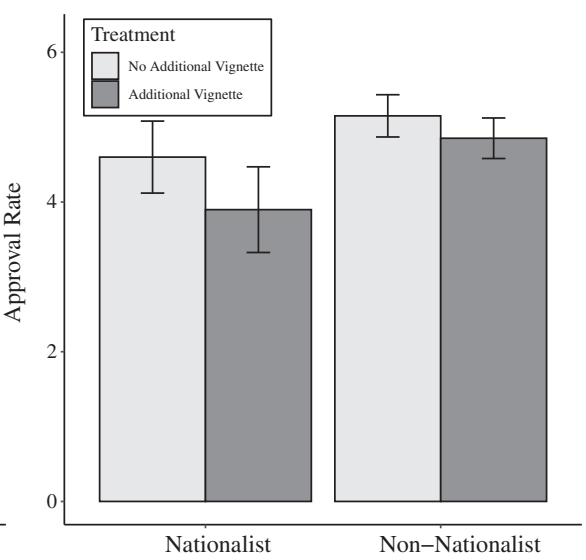

Note: The additional vignette says that the gains enjoyed by Chinese or Country X's citizens would be greater than the gains enjoyed by American citizens. Error bars represent $95 \%$ confidence intervals.

FIGURE 2. Approval rate for removal of import limits by nationalism

67. Coding respondents whose support for the proposed trade policy ranged from 4 to 6 as supporters of the policy, we found that among the groups facing the "remove" scenario, decreases in support were 10.74 percentage points when China was the trade partner $(p=0.0171, n=435)$ and 5.89 percentage points when Country X was the trade partner $(p=0.1456, n=415)$. Among the groups facing the "impose" scenario, decreases in support were 8.22 percentage points when China was the trade partner $(p=0.0842, n=$ 438) and 14.72 percentage points when Country $\mathrm{X}$ was the trade partner $(p=0.0016, n=445)$.

68. To identify nationalists in our sample, we use a prompt from Quek and Johnston 2018: "Everyone should support their country even when it is wrong." Those who agree with this statement are classified as nationalists. This test is randomly administered to three-quarters of our sample, $n=1,305$ (see Appendix D). 
(a)

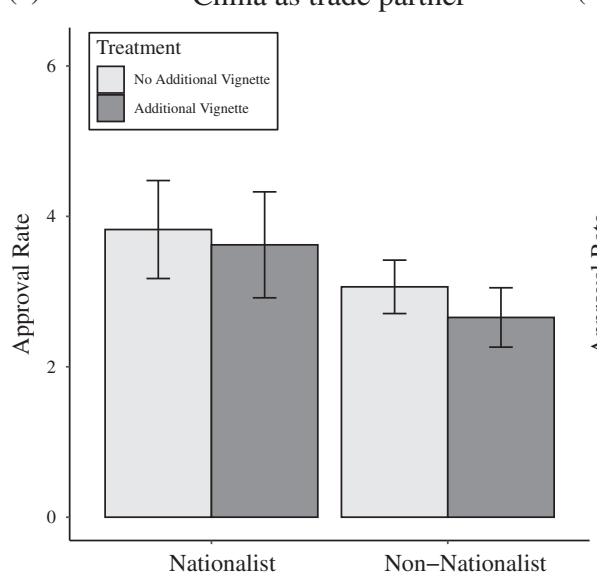

(b)

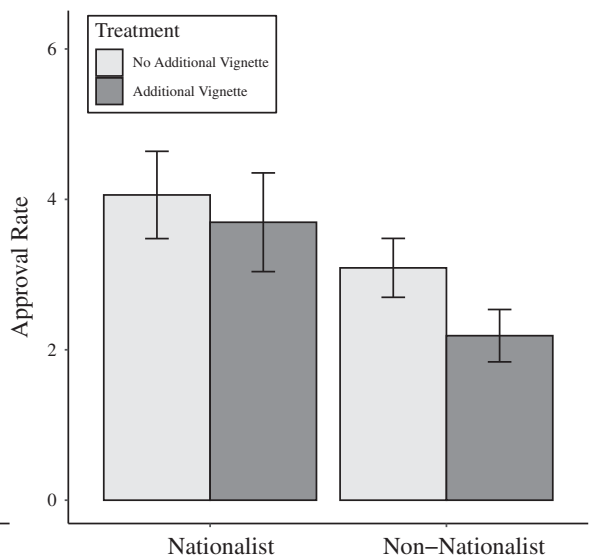

Note: The additional vignette says that the losses suffered by Chinese or Country X's citizens would be greater than the gains enjoyed by American citizens. Error bars represent $95 \%$ confidence intervals.

FIGURE 3. Approval rate for imposition of import limits by nationalism

\section{Which Forms of Other-Regarding Preferences Were at Play?}

The results suggest that social preferences can affect opinion toward trade. But which specific forms of other-regarding preferences were at play? We believe that altruism and advantageous inequality aversion would be most relevant given our experimental design.

An individual is altruistic if "her utility increases with the well being of other people."69 A large body of research has shown that people suffer a moral cost (disutility) from causing harm to others. ${ }^{70}$ In the win-lose scenario, respondents in the treatment group would be actively inflicting negatives on foreign citizens if they supported the proposed trade policy. This could activate their altruism and empathy. Such concerns, however, would not be activated in the win-win scenario because refusing to support the proposed policy would not actively cause harm to foreign citizens compared to the status quo.

Also consistent with our theoretical framework is advantageous inequality aversion, "the loss individuals incur because others have worse material outcomes than

69. Fehr and Schmidt 2006, 638.

70. Reviewed in Crockett et al. 2014, 17,320. Crockett and colleagues also noted that one strand of the literature "predicts that people will value others' pain similarly to how they value their own pain, to the extent that they empathize with the other person," with another strand further suggesting that moral sentiment "could lead some people to evaluate the cost of others' pain as higher than their own in a setting where they feel a degree of responsibility for that pain." 
they do." 71 If this form of inequity aversion operates at the international level, then domestic citizens will incur utility loss when foreign citizens have worse outcomes than they do. In the win-lose scenario where foreigners would have worse outcomes than Americans, the proposed trade policy in the treatment group would generate an even greater welfare gap between domestic and foreign citizens. Respondents driven by advantageous inequality aversion would then be less supportive of the proposed trade policy when they read the treatment vignette. This does not apply in the winwin scenario, however, because there is no advantageous inequality in that scenario.

To track the relevance of altruism and advantageous inequality aversion, we examine the open-ended responses in the win-lose scenario. We focus on whether and how frequently the respondents expressed other-regarding concerns, and what exactly these other-regarding concerns were, across different experimental conditions. This allows us to evaluate the argument that relative-gains considerations, which our experiment directly manipulated, can be offset by the respondent's other-regarding preferences, which are inferred from the data. ${ }^{72}$

We use a two-stage approach to analyze the open-ended responses. First, we categorized responses into four groups: those displaying other-regarding preferences (e.g., "I oppose because it will strongly hurt the other country"); those displaying self-serving preferences (e.g., "Because [I] am selfish and want what is better for my country"); those raising retaliation concerns (e.g., "China owns a significant amount of the United States' debt. It is best not to provoke a trading partner, that has significant leverage over you"); and those that were interpretable but did not fit into any other categories (e.g., "Business does not need government interference. Free trade!"). ${ }^{73}$ Second, we broke down the responses that displayed other-regarding preferences, and classified them according to the type of otherregarding preferences implied: altruism/empathy (e.g., "I don't want anyone to suffer"); equality/fairness (e.g., "We should have equality"); cosmopolitanism (e.g., "I oppose this deal because I am a globalist, not a nationalist"); and others (e.g., "It's not moral").

Our first-stage analysis provides further evidence that in the win-lose scenario individual trade attitudes were influenced by other-regarding preferences (Figure 4). When told that foreign losses outweigh domestic gains, respondents were more likely to justify their views based on their other-regarding preferences on the one hand, and less likely to explain their opinion based on their self-serving preferences on the other hand. Where the trade partner was China, the proportion of other-regarding responses rose by sixteen percentage points $(p=0.0011, n=388)$ when the additional vignette was introduced, while the proportion of self-serving responses

71. Lü, Scheve, and Slaughter 2012, 639.

72. Inferring other-regarding preferences from the data is common in experimental work that studies social preferences. See, for example, Lü, Scheve, and Slaughter 2012.

73. Thirteen percent ( 115 out of 883 ) of the responses were removed because they were not interpretable. This is comparable to the proportions in Davies and Johns 2013 (17\%) and Tomz 2007 (17\%). 
dropped by the same percentage points ( $p=0.0017, n=388$ ). The empirical pattern is nearly identical where the trade partner was Country X. ${ }^{74}$

(a)

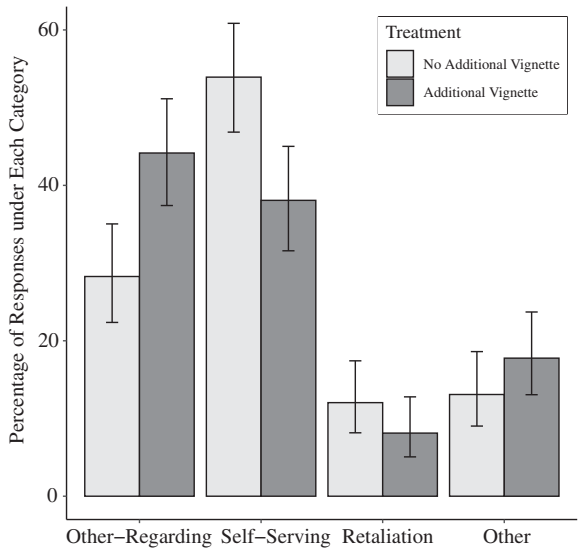

(b) Country $\mathrm{X}$ as trade partner

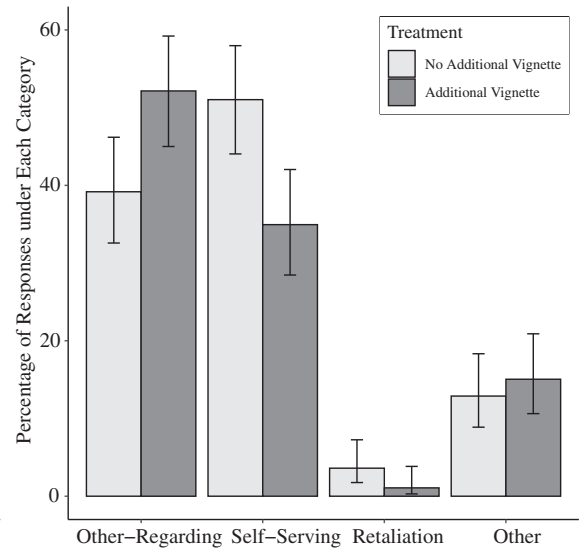

Notes: The additional vignette says that the losses suffered by Chinese or Country X's citizens would be greater than the gains enjoyed by American citizens. For each experimental group, the percentages do not sum up to $100 \%$ because some responses fall into more than one category. Error bars represent $95 \%$ confidence intervals.

FIGURE 4. Coding of open-ended responses by treatment condition in the win-lose scenario

Probing further, our second-stage analysis suggests that altruism and inequality aversion were the most relevant forms of other-regarding preferences expressed in the win-lose scenario. Among respondents who expressed other-regarding preferences in the open-ended responses, most made it clear that they did not want to harm foreign citizens, or that they did not want to make foreign citizens suffer (Figure 5). ${ }^{75}$ Equality and fairness were also important to some respondents. ${ }^{76} \mathrm{~A}$ small minority also viewed themselves as global citizens, and consequently believed

74. The proportion of self-serving responses dropped by sixteen percentage points $(p=0.0016, n=380)$, and the proportion of other-regarding responses rose by thirteen percentage points $(p=0.0111, n=380)$.

75. For example, "I don't agree with anything that would take away something from one party in order to benefit another. I believe there are solutions that can only benefit everyone without harming anyone." Another reads, "I don't want anyone to suffer."

76. For example, "The welfare of the citizens of China are of equal importance." Another reads: "This is not fair to humanity." 
that trade deals should be made in a way that also takes foreign welfare into consideration. ${ }^{77}$

(a)

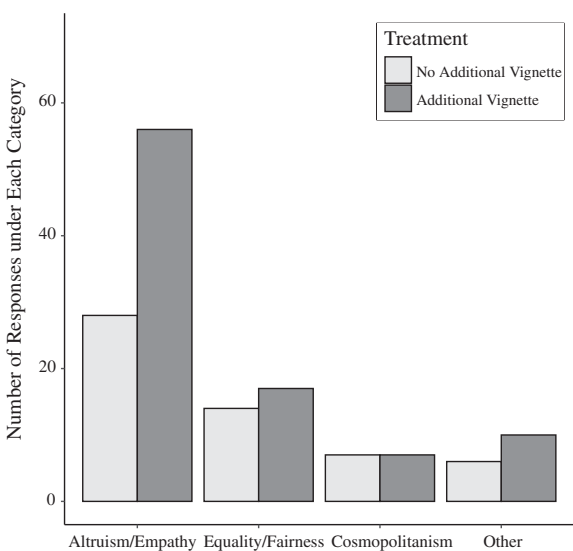

(b) Country $\mathrm{X}$ as trade partner

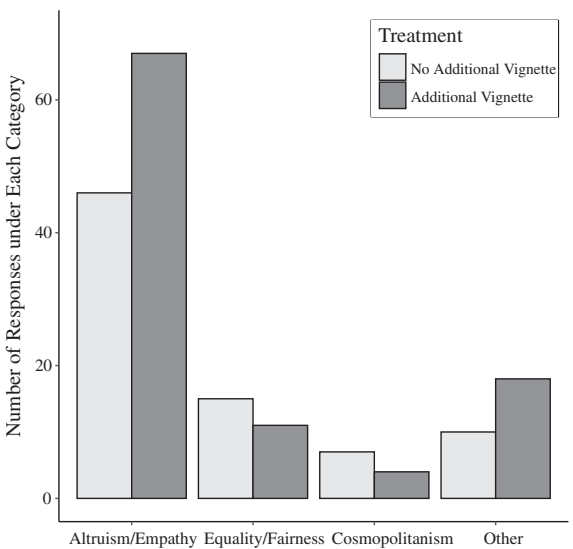

Note: The additional vignette says that the losses suffered by Chinese or Country X's citizens would be greater than the gains enjoyed by American citizens. Interpretable responses numbered 191 and 197 in the control and treatment groups, respectively, where China is the trade partner; and 194 and 186 in the control and treatment groups, respectively, where Country $\mathrm{X}$ is the trade partner.

FIGURE 5. Disaggregation of other-regarding responses by treatment condition in the win-lose scenario

The results suggest that altruism and advantageous inequality aversion contributed to the generally low support for the win-lose trade policy. But alternative explanations should also be considered. First, fears of a trade war could affect our results: respondents might worry that China or Country $\mathrm{X}$ would respond to significant welfare losses by retaliating with a similarly hostile trade policy. ${ }^{78}$ This explanation, while logically possible, seems unlikely as we find no increase in the percentage of open-ended responses that raised such retaliation concerns in the treatment group (Figure 4). To investigate further, we also subset our analysis by individual risk preference (see Appendix D). We find no evidence that risk-averse respondents-who should be more likely to fear retaliation-were systematically more opposed to the trade policy in the win-lose scenario when given the additional vignette. This

77. For example, "I don't agree with all these tariffs and import restrictions. While I am proud of being an American, I see us as part of a larger world, not just looking out for ourselves." Another reads: "It is against globalization. We should think about not only our own country but also think about mutual prosperity as [a] member of the world."

78. We thank an anonymous reviewer for highlighting this possibility. 
further mitigates the concern that the treated respondents in the win-lose scenario reacted the way they did purely due to fears of retaliation from China or Country X.

Another interpretation pertains to respondents' expectation of future cooperativeness from China or Country X. It is possible that respondents strategically avoided causing harm to the trade partner in exchange for more favorable trade policy from China or Country $\mathrm{X}$ in the future. However, while some open-ended responses suggested the importance of free trade, which could be interpreted as evidence in favor of this mechanism, these responses were rare (see the category "Cosmopolitanism" in Figure 5). Nonetheless, that the results were driven by a global form of utilitarianism may be harder to rule out. Our additional vignette in the win-lose scenario may have driven utilitarian concerns in that it implied the global welfare level would decrease due to the proposed trade policy. Although very few open-ended responses displayed such concerns, we find that these responses appeared in the treatment group only, and might hint at a different but potentially very interesting form of other-regarding preferences that is not covered here.

While hand-coded content analysis can help us better understand the motivations and mechanisms behind the respondent's choice, one major shortcoming of manual coding lies in its replicability. To address this concern, we additionally conduct two separate sets of dictionary-based content analyses-one based on the Moral Foundations Dictionary ${ }^{79}$ and the other based on our own dictionary. Their findings converge with each other, as well as with the hand-coded analysis. We document the dictionary-based analyses in detail in Appendix F.

\section{Conclusion}

We show that relative-gains considerations causally affect trade opinion, but not in a "beggar-thy-neighbor" or even a "beggar-thy-rival" situation. Relative gains are important in a win-win scenario: people want to gain more than their foreign trade partner if both sides are gaining. In a win-lose scenario, however, relative-gains considerations can be offset by other-regarding preferences. This applies not only when the trade partner is some unnamed country in general, but also when the trade partner is China in particular. This result is especially interesting because our experiment was conducted in the midst of the China-US trade war, in which mutual antagonism and competition were pronounced. Our findings challenge the conventional wisdom that underlies much of the IR scholarship - as well as much of the political rhetoric on trade - that would lead us to expect support for a trade policy in which the home state always wins.

Our work advances the literature in four ways. This study is the first to experimentally investigate how relative-gains and other-regarding preferences interact in trade. While previous studies have separately focused on the role of relative-gains 
and other-regarding factors, ${ }^{80}$ a key question remains: what if these two forces collide? Knowing the answer to this question is important practically because both factors can come into play in real-world cases. We show that while relative gains are important under a win-win trade policy, other-regarding considerations can offset relative-gains preferences in a win-lose situation.

Second, our findings offer direct evidence on the causal relationship between relative gains and trade opinion. Contrary to previous work, we show that relative gains-seeking behavior can be observed in the full sample that includes a lot of non-Republicans_-and not in Republicans only ${ }^{81}$-insofar as other-regarding concerns are not triggered by the proposed trade policy. ${ }^{82}$ The different findings are likely due to our different research focus, leading to different experimental manipulations: instead of in-group favoritism, ${ }^{83}$ we focus directly on relative gains; instead of manipulating job gains or losses, we informed our respondents directly of the winners and losers to manipulate their perceptions of a country's gains or losses from trade. This ensures that they focus squarely on the relative gains from trade, and that the salience of job losses does not dominate their perceptions.

Third, the findings expand our understanding of the relationship between social preferences and trade opinion. Lü, Scheve, and Slaughter have found that otherregarding preferences at the domestic level influence individual trade opinion. ${ }^{84}$ Brutger and Rathbun have recently shown that social preferences, in the form of inequity aversion, can also influence trade preferences in a win-win scenario. ${ }^{85} \mathrm{We}$ extend from these studies by demonstrating not only that altruism, in addition to inequity aversion, can operate at the international level and affect trade opinion, but also that such social preferences can offset relative-gains considerations in a win-lose scenario. Finally, by showing that beliefs about relative gains at the national level can influence trade opinion at the personal level, our findings support the idea that trade preferences are also guided by sociotropic motivations. ${ }^{86}$

Several avenues open for future research. As our experiment targeted only American citizens, it would be useful to investigate whether relative-gains and other-regarding preferences vary across different countries. In addition, since our experiment emphasized the trade impact on citizens rather than on the countries per se, ${ }^{87}$ it would be interesting for future work to explore whether a frame focusing

80. Lü, Scheve, and Slaughter 2012; Mutz and Kim 2017.

81. Mutz and Kim 2017, 843 .

82. To confirm that this result is not entirely driven by Republicans, we remove the Republicans from our data set and analyze the average treatment effect among groups facing the "remove" scenario against China. The approval rating for the policy is 4.71 in the control group, compared to 4.13 in the treatment group ( $p=$ $0.0070, n=297)$.

83. Mutz and Kim 2017.

84. Lü, Scheve, and Slaughter 2012.

85. Brutger and Rathbun 2021.

86. Fordham 2008; Guisinger 2017; Hearn 2020; Mansfield and Mutz 2009.

87. For relevant work that also focused on the trade impact on citizens, see Hiscox 2006; Mutz and Kim 2017; Rho and Tomz 2017. 
on countries would lead to different outcomes. Moreover, our study did not cover all possible welfare implications of bilateral trade because we did not study the cases where the domestic gains outweigh the trade partner's gains or where the domestic losses outweigh the trade partner's gains. Future research may find it useful to study these two cases of asymmetric trade benefits. Finally, because trade is only one of the many forms of international interactions that create relative-gains concerns, future research should also study how perceptions of relative gains shape public preferences on issues beyond international trade.

\section{Data Availability Statement}

Replication files for this research note may be found at <https:/doi.org/10.7910/ DVN/DEPUUO $>$.

\section{Supplementary Material}

Supplementary material for this research note is available at $<$ https://doi.org/10.1017/ S0020818322000030>.

\section{References}

Andreoni, James. 1990. Impure Altruism and Donations to Public Goods: A Theory of Warm-Glow Giving. Economic Journal 100 (401):464-77.

Andreoni, James, and John Miller. 2002. Giving According to GARP: An Experimental Test of the Consistency of Preferences for Altruism. Econometrica 70 (2):737-53.

Baker, Andy. 2005. Who Wants to Globalize? Consumer Tastes and Labor Markets in a Theory of Trade Policy Beliefs. American Journal of Political Science 49 (4):924-38.

Baldwin, David Allen. 1993. Neorealism and Neoliberalism: The Contemporary Debate. Columbia University Press.

Baldwin, Robert E., and Christopher S. Magee. 2000. Is Trade Policy for Sale? Congressional Voting on Recent Trade Bills. Public Choice 105 (1-2):79-101.

Balistreri, Edward J. 1997. The Performance of the Heckscher-Ohlin-Vanek Model in Predicting Endogenous Policy. Canadian Journal of Economics 30 (1):1-17.

Baumeister, Roy F. 1998. The Self. In The Handbook of Social Psychology, Vol. 1, 4th ed., edited by Daniel Gilbert, Susan Fiske, and Gardner Lindzey, 680-740. McGraw-Hill.

Baumeister, Roy F. 2010. The Self. In Advanced Social Psychology: The State of the Science, edited by Roy F. Baumeister and Eli J. Finkel, 139-75. Oxford University Press.

Beaulieu, Eugene. 2002a. Factor or Industry Cleavages in Trade Policy? An Empirical Analysis of the Stolper-Samuelson Theorem. Economics and Politics 14 (2):99-131.

Beaulieu, Eugene. 2002b. The Stolper-Samuelson Theorem Faces Congress. Review of International Economics 10 (2):343-60.

Beaulieu, Eugene, and Christopher Magee. 2004. Four Simple Tests of Campaign Contributions and Trade Policy Preferences. Economics and Politics 16 (2):163-87. 
Bellemare, Charles, Sabine Kröger, and Arthur van Soest. 2008. Measuring Inequity Aversion in a Heterogeneous Population Using Experimental Decisions and Subjective Probabilities. Econometrica 76 (4):815-39.

Bénabou, Roland, and Jean Tirole. 2006. Incentives and Prosocial Behavior. American Economic Review 96 (5):1652-78.

Berg, Joyce, John Dickhaut, and Kevin McCabe. 1995. Trust, Reciprocity, and Social History. Games and Economic Behavior 10 (1):122-42.

Berinsky, Adam J., Gregory A. Huber, and Gabriel S. Lenz. 2012. Evaluating Online Labor Markets for Experimental Research: Amazon.com's Mechanical Turk. Political Analysis 20 (3):351-68.

Bernhard, Helen, Urs Fischbacher, and Ernst Fehr. 2006. Parochial Altruism in Humans. Nature 442: 912-15.

Blonigen, Bruce A. 2008. New Evidence on the Formation of Trade Policy Preferences. Working paper no. 14627, National Bureau of Economic Research.

Brekke, Kjell Arne, Snorre Kverndokk, and Karine Nyborg. 2003. An Economic Model of Moral Motivation. Journal of Public Economics 87 (9-10):1967-83.

Brutger, Ryan, and Brian Rathbun. 2021. Fair Share? Equality and Equity in American Attitudes Toward Trade. International Organization 75 (3):880-900.

Brutger, Ryan, Joshua D. Kertzer, Jonathan Renshon, Dustin Tingley, and Chagai M. Weiss. Forthcoming. Abstraction and Detail in Experimental Design. American Journal of Political Science.

Busch, Marc L., and Eric R. Reinhardt. 1993. Nice Strategies in a World of Relative Gains: The Problem of Cooperation Under Anarchy. Journal of Conflict Resolution 37 (3):427-45.

Charness, Gary, and Matthew Rabin. 2002. Understanding Social Preferences with Simple Tests. Quarterly Journal of Economics 117 (3):817-69.

Coppock, Alexander. 2019. Generalizing from Survey Experiments Conducted on Mechanical Turk: A Replication Approach. Political Science Research and Methods 7 (3):613-28.

Coppock, Alexander, Thomas J. Leeper, and Kevin J. Mullinix. 2018. Generalizability of Heterogeneous Treatment Effect Estimates Across Samples. Proceedings of the National Academy of Sciences 115 (49): 12441-46.

Crocker, Jennifer, Marc-Andre Olivier, and Noah Nuer. 2009. Self-Image Goals and Compassionate Goals: Costs and Benefits. Self and Identity 8 (2-3):251-69.

Crockett, Molly J., Zeb Kurth-Nelson, Jenifer Z. Siegel, Peter Dayan, and Raymond J. Dolan. 2014. Harm to Others Outweighs Harm to Self in Moral Decision Making. Proceedings of the National Academy of Sciences 111 (48):17320-25.

Davies, Graeme A.M., and Robert Johns. 2013. Audience Costs Among the British Public: The Impact of Escalation, Crisis Type, and Prime Ministerial Rhetoric. International Studies Quarterly 57 (4):725-37.

Davis, James W. 2000. Threats and Promises: The Pursuit of International Influence. Johns Hopkins University Press.

Deci, Edward L., and Richard M. Ryan. 2000. The "What" and "Why" of Goal Pursuits: Human Needs and the Self-Determination of Behavior. Psychological Inquiry 11 (4):227-68.

Engelmann, Dirk, and Martin Strobel. 2004. Inequality Aversion, Efficiency, and Maximin Preferences in Simple Distribution Experiments. American Economic Review 94 (4):857-69.

Fehr, Ernst, and Urs Fischbacher. 2002. Why Social Preferences Matter: The Impact of Non-selfish Motives on Competition, Cooperation and Incentives. Economic Journal 112:C1-C33.

Fehr, Ernst, Daniela Glätzle-Rützler, and Matthias Sutter. 2013. The Development of Egalitarianism, Altruism, Spite and Parochialism in Childhood and Adolescence. European Economic Review 64: 369-83.

Fehr, Ernst, and Klaus M. Schmidt. 1999. A Theory of Fairness, Competition, and Cooperation. Quarterly Journal of Economics 114 (3):817-68.

Fehr, Ernst, and Klaus M. Schmidt. 2006. The Economics of Fairness, Reciprocity, and Altruism: Experimental Evidence and New Theories. In Handbook on the Economics of Giving, Reciprocity, and Altruism, edited by Serge-Christophe Kolm and Jean Mercier Ythier, 615-91. Elsevier. 
Filkowski, Megan M., R. Nick Cochran, and Brian W. Haas. 2016. Altruistic Behavior: Mapping Responses in the Brain. Neuroscience and Neuroeconomics 5:65-75.

Fong, Christina M., Samuel Bowles, and Herbert Gintis. 2006. Strong Reciprocity and the Welfare State. In Handbook of the Economics of Giving, Altruism and Reciprocity, edited by Serge-Christophe Kolm and Jean Mercier Ythier, 1439-64. Amsterdam: Elsevier.

Fordham, Benjamin O. 2008. Economic Interests and Public Support for American Global Activism. International Organization 62 (1):163-82.

Forsythe, Robert, Joel L. Horowitz, Nathan E. Savin, and Martin Sefton. 1994. Fairness in Simple Bargaining Experiments. Games and Economic Behavior 6 (3):347-69.

Funk, Carolyn L. 2000. The Dual Influence of Self-Interest and Societal Interest in Public Opinion. Political Research Quarterly 53 (1):37-62.

Glaser, Charles L. 1994. Realists As Optimists: Cooperation As Self-Help. International Security 19 (3): 50-90.

Goette, Lorenz, David Huffman, and Stephan Meier. 2006. The Impact of Group Membership on Cooperation and Norm Enforcement: Evidence Using Random Assignment to Real Social Groups. American Economic Review 96 (2):212-16.

Goodman, Joseph K., Cynthia E. Cryder, and Amar Cheema. 2013. Data Collection in a Flat World: The Strengths and Weaknesses of Mechanical Turk Samples. Journal of Behavioral Decision Making 26 (3): 213-24.

Gowa, Joanne. 1989. Bipolarity, Multipolarity, and Free Trade. American Political Science Review 83 (4): 1245-56.

Gowa, Joanne, and Edward D. Mansfield. 1993. Power Politics and International Trade. American Political Science Review 87 (2):408-20.

Graham, Jesse, Brian A. Nosek, Jonathan Haidt, Ravi Iyer, Spassena Koleva, and Peter H. Ditto. 2011. Mapping the Moral Domain. Journal of Personality and Social Psychology 101 (2):366-85.

Grieco, Joseph M. 1988a. Anarchy and the Limits of Cooperation: A Realist Critique of the Newest Liberal Institutionalism. International Organization 42 (3):485-507.

Grieco, Joseph M. 1988b. Realist Theory and the Problem of International Cooperation: Analysis with an Amended Prisoner's Dilemma Model. Journal of Politics 50 (3):600-24.

Grieco, Joseph M. 1990. Cooperation Among Nations: Europe, America, and Non-tariff Barriers to Trade. Cornell University Press.

Guisinger, Alexandra. 2017. American Opinion on Trade: Preferences without Politics. Oxford University Press.

Güth, Werner, Rolf Schmittberger, and Bernd Schwarze. 1982. An Experimental Analysis of Ultimatum Bargaining. Journal of Economic Behavior and Organization 3 (4):367-88.

Hainmueller, Jens, and Michael J. Hiscox. 2006. Learning to Love Globalization: Education and Individual Attitudes Toward International Trade. International Organization 60 (2):469-98.

Hainmueller, Jens, and Daniel J. Hopkins. 2015. The Hidden American Immigration Consensus: A Conjoint Analysis of Attitudes Toward Immigrants. American Journal of Political Science 59 (3):529-48.

Hauser, David J., and Norbert Schwarz. 2016. Attentive Turkers: MTurk Participants Perform Better on Online Attention Checks Than Do Subject Pool Participants. Behavior Research Methods 48 (1): $400-407$.

Hays, Jude C., Sean Ehrlich, and Clint Peinhardt. 2005. Government Spending and Public Support for Trade in the OECD: An Empirical Test of the Embedded Liberalism Thesis. International Organization 59 (2):271-88.

Hearn, Eddie. 2014. Harm, Fairness and Trade Policy Preferences: An Experimental Examination of Sincere Fair-Trade Preferences. International Politics 51 (4):124-35.

Hearn, Eddie. 2020. Disentangling the Relationship Between Sociotropic and Egotropic Trade Attitudes: A Survey Experiment in Japan. Japanese Journal of Political Science 21 (1):31-42.

Herrmann, Richard K., Philip E. Tetlock, and Matthew N. Diascro. 2001. How Americans Think About Trade: Reconciling Conflicts Among Money, Power, and Principles. International Studies Quarterly 45 (2):191-218. 
Hiscox, Michael J. 2006. Through a Glass and Darkly: Attitudes Toward International Trade and the Curious Effects of Issue Framing. International Organization 60 (3):755-80.

Hoffman, Michael E. S. 2010. Job Losses and Perceptions of Globalization. Journal of World Trade 44 (5): 967-83.

Huff, Connor, and Joshua D. Kertzer. 2018. How the Public Defines Terrorism. American Journal of Political Science 62 (1):55-71.

Irwin, Douglas A. 1994. The Political Economy of Free Trade: Voting in the British General Election. Journal of Law and Economics 37 (1):75-108.

Irwin, Douglas A. 1996. Industry or Class Cleavages over Trade Policy? Evidence from the British General Election of 1923. In The Political Economy of Trade Policy: Papers in Honor of Jagdish Bhagwati, edited by Robert C. Feenstra, Gene M. Grossman, and Douglas A. Irwin, 53-75. MIT Press.

Jervis, Robert. 1992. Political Implications of Loss Aversion. Political Psychology 13 (2):187-204.

Johns, Robert, and Graeme A.M. Davies. 2012. Democratic Peace or Clash of Civilizations? Target States and Support for War in Britain and the United States. Journal of Politics 74 (4):1038-52.

Johnson, Tim, Christopher T. Dawes, James H. Fowler, Richard McElreath, and Oleg Smirnov. 2009. The Role of Egalitarian Motives in Altruistic Punishment. Economic Letters 102:192-94.

Jones, Calvert W., and Teresa M. Bejan. 2021. Reconsidering Tolerance: Insights from Political Theory and Three Experiments. British Journal of Political Science 51 (2):604-23.

Jones, Ronald W. 1971. A Three-Factor Model in Theory, Trade, and History. In Trade, Balance of Payments, and Growth: Papers in Honor of Charles P. Kindleberger, edited by Jagdish Bhagwati, Ronald Jones, Robert Mundell, and Jaroslav Vanek, 3-21. North Holland.

Kaempfer, William H., and Stephen V. Marks. 1993. The Expected Effects of Trade Liberalisation: Evidence from US Congressional Action on Fast-Track Authority. World Economy 16 (6):725-40.

Kahneman, Daniel, and Jack L. Knetsch. 1992. Valuing Public Goods: The Purchase of Moral Satisfaction. Journal of Environmental Economics and Management 22 (1):57-70.

Kertzer, Joshua D., and Brian C. Rathbun. 2015. Fair Is Fair: Social Preferences and Reciprocity in International Politics. World Politics 67 (4):613-55.

Kinder, Donald R., and D. Roderick Kiewiet. 1981. Sociotropic Politics: The American Case. British Journal of Political Science 11 (2):129-61.

Krugman, Paul R., Maurice Obstfeld, and Marc J. Melitz. 2012. International Economics: Theory and Policy, 9th ed. Addison-Wesley.

Krupnikov, Yanna, and Adam Seth Levine. 2014. Cross-Sample Comparisons and External Validity. Journal of Experimental Political Science 1 (1):59-80.

Levitt, Steven D., and John A. List. 2007. What Do Laboratory Experiments Measuring Social Preferences Reveal About the Real World? Journal of Economic Perspectives 21 (2):153-74.

Levy, Jack S. 1992. Prospect Theory and International Relations: Theoretical Applications and Analytical Problems. Political Psychology 13 (2):283-310.

Lipson, Charles. 1984. International Cooperation in Economic and Security Affairs. World Politics 37 (1): $1-23$.

Lü, Xiaobo, Kenneth Scheve, and Matthew J. Slaughter. 2012. Inequity Aversion and the International Distribution of Trade Protection. American Journal of Political Science 56 (3):638-54.

Mansfield, Edward D., and Diana C. Mutz. 2009. Support for Free Trade: Self-Interest, Sociotropic Politics, and Out-Group Anxiety. International Organization 63 (3):425-57.

Margalit, Yotam. 2011. Costly Jobs: Trade-Related Layoffs, Government Compensation, and Voting in US Elections. American Political Science Review 105 (1):166-88.

Matthews, John C. 1996. Current Gains and Future Outcomes: When Cumulative Relative Gains Matter. International Security 21 (1):112-46.

Mastanduno, Michael. 1991. Do Relative Gains Matter? America's Response to Japanese Industrial Policy. International Security 16 (1):73-113.

Mayda, Anna M., and Dani Rodrik. 2005. Why Are Some People (and Countries) More Protectionist than Others? European Economic Review 49 (6):1393-430. 
Morrow, James D. 1997. When Do "Relative Gains" Impede Trade? Journal of Conflict Resolution 41 (1): $12-37$.

Mutz, Diana C. 1992. Mass Media and the Depoliticization of Personal Experience. American Journal of Political Science 36 (2):483-508.

Mutz, Diana C., and Eunji Kim. 2017. The Impact of In-Group Favoritism on Trade Preferences. International Organization 71 (4):827-50.

Naoi, Megumi. 2020. Survey Experiments in International Political Economy: What We (Don't) Know About the Backlash Against Globalization. Annual Review of Political Science 23:333-56.

O'Rourke, Kevin H., and Richard Sinnott. 2001. The Determinants of Individual Trade Policy Preferences: International Survey Evidence. In Brookings Trade Forum: 2001, edited by Susan M. Collins and Dani Rodrik, 157-206. Brookings Institution.

Paolacci, Gabriele, Jesse Chandler, and Panagiotis G. Ipeirotis. 2010. Running Experiments on Amazon Mechanical Turk. Judgment and Decision Making 5 (5):411-19.

Powell, Robert. 1991. Absolute and Relative Gains in International Relations Theory. American Political Science Review 85 (4):1303-20.

Quek, Kai, and Alastair Iain Johnston. 2018. Can China Back Down? Crisis De-escalation in the Shadow of Popular Opposition. International Security 42 (3):7-36.

Ray, Edward John. 1987. Changing Patterns of Protectionism: The Fall in Tariffs and the Rise in NonTariff Barriers. Northwestern Journal of International Law and Business 8 (2):285-327.

Rho, Sungmin, and Michael Tomz. 2017. Why Don't Trade Preferences Reflect Economic Self-Interest? International Organization 71 (S1):S85-S108.

Rousseau, David L. 2002. Motivations for Choice: The Salience of Relative Gains in International Politics. Journal of Conflict Resolution 46 (3):394-426.

Sabet, Shahrzad. 2013. What's in a Name? Isolating the Effect of Prejudice on Individual Trade Preferences. Unpublished manuscript, available at <https://ssrn.com/abstract=2301118>.

Samuelson, Paul A. 1971. Ohlin Was Right. Swedish Journal of Economics 73 (4):365-84.

Scheve, Kenneth F., and Matthew J. Slaughter. 2001. What Determines Individual Trade-Policy Preferences? Journal of International Economics 54 (2):267-92.

Sears, David O., and Carolyn L. Funk. 1990. Self-Interest in Americans' Political Opinions. In Beyond SelfInterest, edited by Jane J. Mansbridge, 147-70. University of Chicago Press.

Snidal, Duncan. 1991a. International Cooperation Among Relative Gains Maximizers. International Studies Quarterly 35 (4):387-402.

Snidal, Duncan. 1991b. Relative Gains and the Pattern of International Cooperation. American Political Science Review 85 (3):701-26.

Stolper, Wolfgang F., and Paul A. Samuelson. 1941. Protection and Real Wages. Review of Economic Studies 9 (1):58-73.

Tomz, Michael. 2007. Domestic Audience Costs in International Relations: An Experimental Approach. International Organization 61 (4):821-40.

Tomz, Michael R., and Jessica L.P. Weeks. 2013. Public Opinion and the Democratic Peace. American Political Science Review 107 (4):849-65.

Tricomi, Elizabeth, Antonio Rangel, Colin F. Camerer, and John P. O'Doherty. 2010. Neural Evidence for Inequality-Averse Social Preferences. Nature 463:1089-91.

Waltz, Kenneth. 1959. Man, the State, and War: A Theoretical Analysis. Columbia University Press.

Waltz, Kenneth. 1979. Theory of International Politics. Addison-Wesley.

Werner, Suzanne. 1997. In Search of Security: Relative Gains and Losses in Dyadic Relations. Journal of Peace Research 34 (3):289-302.

Wike, Richard, and Kat Devlin. 2018. As Trade Tensions Rise, Fewer Americans See China Favorably. Pew Research Center, 28 August. Available at $<$ http://pewrsr.ch/37BTlGe $>$.

Yarhi-Milo, Keren, Joshua D. Kertzer, and Jonathan Renshon. 2018. Tying Hands, Sinking Costs, and Leader Attributes. Journal of Conflict Resolution 62 (10):2150-79. 


\section{Authors}

Eddy S.F. Yeung is a PhD student in the Department of Political Science at Emory University. He can be reached at shing.fung.yeung@emory.edu.

Kai Quek is Associate Professor in the Department of Politics and Public Administration at the University of Hong Kong. He can be reached at quek@hku.hk.

\section{Acknowledgments}

We thank Wilfred Chow, Jennifer Gandhi, Su-Hyun Lee, Renard Sexton, and participants at the 2019 MPSA Annual Conference in Chicago for their feedback and John Koo and Jiaqian Ni for their research assistance. We also thank the editors and anonymous reviewers at $I O$ for their valuable suggestions and advice. The standard disclaimers apply.

\section{Funding}

We thank Hong Kong University and the education fund of the Research Grants Council of Hong Kong for financial support.

\section{Key Words}

Relative gains; trade; public opinion; survey experiment

Date received: February 17, 2021; Date accepted: December 4, 2021 